\title{
Article \\ Multitarget Stool mRNA Test for Detecting Colorectal Cancer Lesions Including Advanced Adenomas
}

\author{
Elizabeth Herring ${ }^{1,2}$, Éric Tremblay ${ }^{1,2}$, Nathalie McFadden ${ }^{2,3}{ }^{\circledR}$, Shigeru Kanaoka ${ }^{4}$ and \\ Jean-François Beaulieu 1,2,*(D) \\ 1 Laboratory of Intestinal Physiopathology, Faculty of Medicine and Health Sciences, Université de Sherbrooke, \\ Sherbrooke, QC J1H 5N4, Canada; elizabeth.herring@usherbrooke.ca (E.H.); \\ eric.tremblay@usherbrooke.ca (É.T.) \\ 2 Centre de Recherche du Centre Hospitalier, Universitaire de Sherbrooke, Sherbrooke, QC J1H 5N4, Canada; \\ nathalie.mc.fadden@usherbrooke.ca \\ 3 Department of Surgery, Faculty of Medicine and Health Sciences, Universite de Sherbrooke, \\ Sherbrooke, QC J1H 5N4, Canada \\ 4 Department of Gastroenterology, Hamamatsu Medical Center, Naka-ku, Hamamatsu 432-8580, Japan; \\ kanaoka@hmedc.or.jp \\ * Correspondence: jean-francois.beaulieu@usherbrooke.ca; Tel.: +1-819-821-8000
}

check for updates

Citation: Herring, E.; Tremblay, É.; McFadden, N.; Kanaoka, S.; Beaulieu, J.-F. Multitarget Stool mRNA Test for Detecting Colorectal Cancer Lesions Including Advanced Adenomas. Cancers 2021, 13, 1228. https:// $10.3390 /$ cancers 13061228

Academic Editor: Takaya Shimura

Received: 25 February 2021

Accepted: 10 March 2021

Published: 11 March 2021

Publisher's Note: MDPI stays neutral with regard to jurisdictional claims in published maps and institutional affiliations.

Copyright: (c) 2021 by the authors. Licensee MDPI, Basel, Switzerland. This article is an open access article distributed under the terms and conditions of the Creative Commons Attribution (CC BY) license (https:// creativecommons.org/licenses/by/ $4.0 /)$.
Simple Summary: Colorectal cancer is still one of the deadliest cancers, even though its detection at early stages has been shown to be a key factor for reducing mortality. Screening methods are available, but their efficacy for detecting early-stage lesions is limited. In the present discovery stage study, we used a targeted mRNA assay in the stools to optimize the identification of patients bearing precancerous lesions as well as colorectal cancers at curable stages with only five targets, thus compatible with standard multiplex PCR. Although further validation is required, this assay has high potential for improving colorectal cancer screening efficacy.

Abstract: Current approved non-invasive screening methods for colorectal cancer (CRC) include FIT and DNA-FIT testing, but their efficacy for detecting precancerous lesions that are susceptible to progressing to CRC such as advanced adenomas (AA) remains limited, thus requiring further options to improve the detection of CRC lesions at earlier stages. One of these is host mRNA stool testing. The aims of the present study were to identify specific stool mRNA targets that can predict AA and to investigate their stability under a clinical-like setting. A panel of mRNA targets was tested on stool samples obtained from 102 patients including $78 \mathrm{CRC}$ stage I-III and $24 \mathrm{AA}$ as well as 32 healthy controls. Area under the receiver operating characteristic (ROC) curves were calculated to establish sensitivities and specificities for individual and combined targets. Stability experiments were performed on freshly obtained specimens. Six of the tested targets were found to be specifically increased in the stools of patients with CRC and three in the stools of both AA and CRC patients. After optimization for the choice of the 5 best markers for AA and CRC, ROC curve analysis revealed overall sensitivities of $75 \%$ and $89 \%$ for AA and CRC, respectively, for a $\geq 95 \%$ specificity, and up to $75 \%$ and $95 \%$ for AA and CRC, respectively, when combined with the FIT score. Targets were found to be stable in the stools up to 3 days at room temperature. In conclusion, these studies show that the detection of host mRNA in the stools is a valid approach for the screening of colorectal cancerous lesions at all stages and is applicable to a clinical-like setup.

Keywords: colorectal cancer; advanced adenoma; screening; stool; mRNA

\section{Introduction}

Colorectal cancer (CRC) is one of the few cancer types for which screening has been proven to reduce cancer mortality in average-risk individuals [1]. Indeed, the spread of the disease in terms of local invasion as well as to lymph nodes and distant organs at 
the time of diagnosis is an important prognostic factor, with five-year survival rates of more than $90 \%$ for individuals with localized lesions but only $~ 10 \%$ for those having their CRC metastasized to distal organs [2]. Early detection is thus a key factor in reducing mortality from CRC [3,4]. Advanced adenomas (AA) are also important to detect since they are considered to be the precursors of CRC $[5,6]$, while non-advanced adenomas $(<1 \mathrm{~cm}$ without advanced histology) may not be associated with increased colorectal cancer risk [6]. Several screening regiments for CRC and AA are recommended such as fecal occult blood testing and colonoscopy. While colonoscopy remains the gold standard for the detection of colorectal lesions, compliance is not optimal owing to discomfort and unpleasant preparation procedures [7]. The risk of complications, cost and access are other limitations of this procedure [8]. On the other hand, the improved immunological version of fecal occult blood testing also referred to as the fecal immunochemical test (FIT), which detects human hemoglobin, has been used for some time with some success [1] but poor precursor lesion detection rates (66-80\% sensitivity for CRC but only $10-28 \%$ for AA) albeit an excellent specificity (93-95\%) limits its effectiveness [3,9-12]. It is therefore imperative to explore alternate or complementary strategies with the potential to improve CRC screening performance, especially for the detection of cancers at their early stages and AA.

In this context, a number of initiatives have been undertaken over the last ten years, from stool testing as a noninvasive approach [1] to the implementation of personalized CRC screening [13] trying to meet with desirable features for a CRC screening test [3]. Interestingly, many of the stool-based testing strategies are based on the high rate of tumor cell exfoliation into the colon-rectal lumen, a parameter that appears to be independent of blood release [14-17]. One of the best documented strategies is the FDA-approved multitarget stool DNA test, an approach based on the detection of specific DNA aberrations from the CRC cells shed into the stools in combination with FIT, which results in an improvement of sensitivity for both CRC (92.3\%) and AA (42.4\%) detection compared to FIT alone, although achieved through a reduction in specificity to $87 \%$ thus generating almost three times more false positives [18]. At first sight, the cost-benefit of such new methods for the medical system may temper screening recommendations [19] but the high cost of CRC treatment, particularly for more advanced disease, is considered to improve the cost-effectiveness of CRC screening [20,21]. Furthermore, higher threshold costs for a biomarker test that could significantly increase the sensitivity of AA detection while maintaining reasonable specificity, would likely be cost-effective relative to currently available noninvasive tests [22,23].

Still based on the significant exfoliation of dysplastic cells from colorectal lesions into the lumen, host mRNA has also been investigated in the stools as a potential biomarker. While isolated from purified exfoliated colonocytes [24] or directly extracted from the stools [25,26], host mRNA has been found to be a reliable source of biomarkers for detecting colorectal cancers. Further analysis confirmed the target mRNAs originated from the tumor or surrounding mucosa and that expression was affected by the number of exfoliated tumor cells, exfoliation of inflammatory cells, tumor size and transcript expression level in the tumor but not primary vs. distal location [27]. More recently, based on the analysis of a series of transcripts previously reported to be upregulated in CRC cells [27-29] or linked to CRC recurrence [30], it has been demonstrated that the inclusion of a multitarget mRNA assay significantly strengthens both sensitivity and specificity for CRC detection [31,32]. Droplet digital PCR was also evaluated as a potential alternative to qPCR for stool mRNA multiplex analysis [33]. However, one important question that remains to be tested for the validation of a multitarget stool mRNA test pertains to AA detection since, up to now, ITGA6 is the only target found to be overrepresented in stool samples of patients bearing AA [32]. Another aspect that needs to be evaluated before considering a potential clinical implementation is the robustness of the test under realistic preservation conditions, as mRNA are considered to be relatively susceptible to degradation in the stools [34,35]. 


\section{Materials and Methods}

\subsection{Patients and Samples}

Two sets of patient samples were used in the study. Both sets were analyzed retrospectively. The first set of samples was collected from patients and healthy controls from the Hamamatsu University School of Medicine with written informed consent. The study was approved by the Institutional Research Ethics Committee of the Hamamatsu University School of Medicine. Complete information about this set has been provided in previous studies [31-33] which was further investigated to find the new data reported in this paper. Briefly, the study cohort used herein included 24 patients with AA defined as being $10 \mathrm{~mm}$ or larger at their greatest dimension and 78 patients with CRC (24 stage I, 32 stage II and 22 stage III) diagnosed by colonoscopy and histopathology as well as 32 healthy controls. For controls and AA, stool samples were collected before colonoscopy. The FIT was performed on all patients and controls as described [32].

The second set of samples was collected from 3 healthy controls and 3 patients diagnosed with CRC stage II or III by colonoscopy and histopathology from the Centre Hospitalier Universitaire de Sherbrooke (CHUS) with written informed consent. The study was approved by the Institutional Research Ethics Committee of the CHUS. This set of samples was used for mRNA target stability experiments. Each sample was split into 13 aliquots stored under various conditions for up to 5 days as follows: \#1, 5 days at $-80{ }^{\circ} \mathrm{C}$ used as control; \#2, 5 days at $-20^{\circ} \mathrm{C}$; \#3, 5 days at $-20^{\circ} \mathrm{C}$ with a thaw / freeze cycle; \#4-8, $1-5$ days at $4{ }^{\circ} \mathrm{C}$ and $\# 9-13,1-5$ days at $23^{\circ} \mathrm{C}$.

\subsection{RNA Isolation, Reverse Transcription, Preamplification, and PCR Amplification}

RNA was isolated from fecal samples and reverse transcribed as described previously [27,36]. For preamplification, the TaqMan PreAmp Master Kit (Applied Biosystems, Thermo Fisher Scientific, Mississauga, ON, Canada) was used to provide unbiased, multiplex preamplification of specific amplicons for analysis with TaqMan gene expression assays [33]. Commercially available TaqMan primer and probe mixtures were used for the preamplification of the 27 preselected targets as described before [33] and detailed in Table 1. Quantitative polymerase chain reaction (qPCR) was performed using the TaqMan Gene Expression Assay with conditions described previously [31].

\subsection{Data Presentation and Statistical Analysis}

Stool mRNA data were calculated as copy number per $\mu \mathrm{L}$ of reaction. For each transcript, a standard reference curve was generated using a serial fivefold dilution of a cDNA stock solution of the target sequence quantified on a NanoDrop 1000 Spectrophotometer (NanoDrop, Wilmington, DE, USA). Prism 8 was used for calculating statistics. Comparison mRNA expression (in copy number) in stool controls and patients with AA and CRC stage I-III lesions were expressed as median with interquartile range and analyzed by the Kruskal-Wallis test followed by Dunn's multiple comparison test. Area under the receiver operating characteristic (ROC) curves were calculated to establish sensitivities and specificities for each marker expressed in \% with a 95\% confidence interval. Scores were calculated for each marker on a scale of 0 to 3 on the basis of three cut-off values established from the ROC curve: (the lower cut-off corresponding to a sensitivity of $80 \%$, medium cut-off corresponding to a specificity of $90 \%$ and higher cut-off corresponding to a specificity of $99 \%$ ) as established previously [32]. Statistical significance was defined as $p<0.05$. 
Table 1. List of specific targets tested.

\begin{tabular}{|c|c|c|c|c|}
\hline \multirow{2}{*}{ Gene Name } & \multirow{2}{*}{ TaqMan Assay I.D. } & \multirow{2}{*}{$\begin{array}{c}\text { Consistently } \\
\text { Detected in Stools }\end{array}$} & \multicolumn{2}{|c|}{ Over-Represented } \\
\hline & & & CRC Only & AA and CRC \\
\hline BGN & Hs00156076_m1 & & & \\
\hline CEACAM5 & Hs00944025_m1 & $\mathrm{Y}$ & & $\mathrm{Y}$ \\
\hline CTNNB1 & Hs00355049_m1 & & & \\
\hline DYNC2H1 & Hs00941787_m1 & & & \\
\hline FAP & Hs00990806_m1 & & & \\
\hline GADD45B & Hs00169587_m1 & $\mathrm{Y}$ & $\mathrm{Y}$ & \\
\hline GLI1 & Hs00171790_m1 & & & \\
\hline HMAN1B1 & Hs01032463_m1 & & & \\
\hline HNRNPA2B1 & Hs00955384_m1 & & & \\
\hline INHBA & Hs04187260_m1 & & & \\
\hline ITGA1 & Hs00235006_m1 & $\mathrm{Y}$ & & \\
\hline ITGA2 & Hs01673848_m1 & $\mathrm{Y}$ & & \\
\hline ITGA6A & Hs01041013_m1 & $\mathrm{Y}$ & $\mathrm{Y}$ & \\
\hline ITGA6 & Hs01041011_m1 & $\mathrm{Y}$ & & $\mathrm{Y}$ \\
\hline KI67 & Hs01032434_m1 & & & \\
\hline KIF3A & Hs01126351_m1 & & & \\
\hline KIF7 & Hs00419527_m1 & & & \\
\hline MACC1 & Hs00766186_m1 & $\mathrm{Y}$ & & $\mathrm{Y}$ \\
\hline MLH1 & Hs00179866_m1 & $\mathrm{Y}$ & & \\
\hline MSH1 & Hs00954125_m1 & $\mathrm{Y}$ & & \\
\hline MTR & Hs01090031_m1 & & & \\
\hline MYBL2 & Hs00942543_m1 & $\mathrm{Y}$ & $\mathrm{Y}$ & \\
\hline MYC & Hs00153408_m1 & $\mathrm{Y}$ & $\mathrm{Y}$ & \\
\hline PTGS2 & Hs00153133_m1 & $\mathrm{Y}$ & $\mathrm{Y}$ & \\
\hline S100A4 & Hs00243202_m1 & $\mathrm{Y}$ & $\mathrm{Y}$ & \\
\hline VDAC2 & Hs01075603_m1 & & & \\
\hline
\end{tabular}

All primer and probe mixtures were first tested on a subset of stool samples including controls, AA and CRC to select those that were consistently detectable in the stools. Further analysis on the whole set of samples allowed the selection of those specifically enriched in CRC and AA or only CRC.

\section{Results}

In this study, we first screened 27 specific targets chosen on the basis of their reported over expression in colorectal cancerous lesions. Preliminary evaluation of these using a subset of 30 samples (10 controls, $10 \mathrm{AA}$ and $10 \mathrm{CRC}$ ) revealed that 14 were consistently detected in the stools of patients bearing colorectal lesions (Table 1). Further testing with other primer and probe mixtures for poorly detected targets was tried but not further studied herein, since 14 appeared to be enough to run the validation assay considering that for a clinical assay, the multiplex PCR capacity is limited to four to five targets depending on the equipment provided by the manufacturer.

Further investigation of the 14 targets was performed on the set of 132 samples obtained from healthy controls $(n=32)$ and patients bearing colorectal lesions $(n=24$ AA and 78 CRC). As detailed in Table 1, six of the targets were found to be significantly over-represented in samples from patients with CRC while three identified patients bearing AA or CRC. As shown in Figure 1, the median copy numbers for the transcripts of the 
first group which included GADD45B, ITGA2, MYBL2, MYC, PTGS2 and S100A4 were found to be significantly increased in the stools of patients with CRC as compared with the controls, while only three, including CEACAM5, ITGA6 and MACC1, were found to be over-represented also in patients with AA.
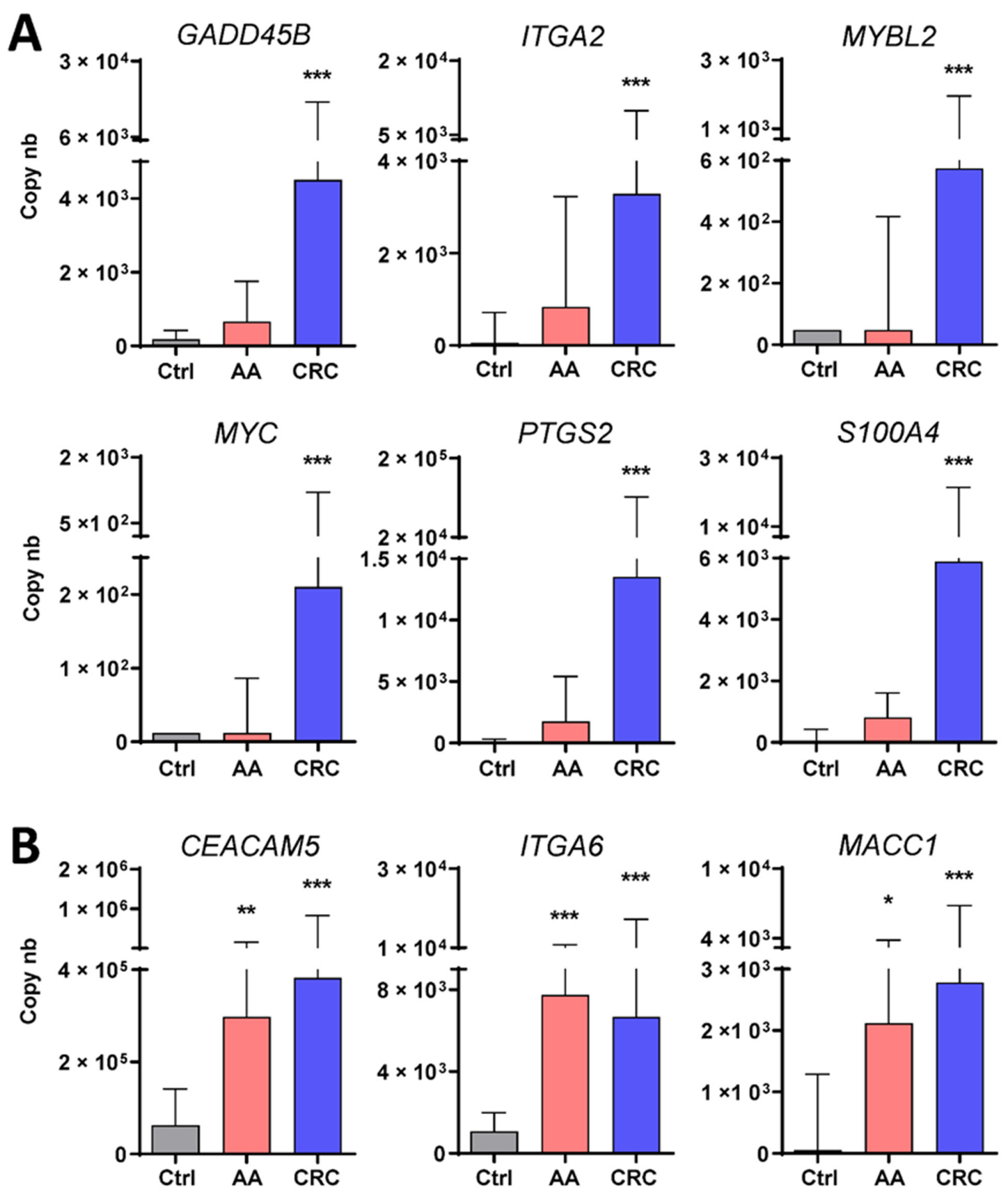

Figure 1. Detection and analysis of selected mRNA targets found to be overrepresented in stool samples of patients with colorectal cancer (CRC) stages I-III (A) or advanced adenomas (AA) (B). A significant increase was observed for the targets GADD45B, ITGA2, MYBL2, MYC, PTGS2 and S100A4 in CRC stages I-III as compared to controls (Ctrl) while for three of the targets, CEACAM5, ITGA6 and MACC1, a significant increase was observed in samples from patients with CRC stages I-III or AA as compared to controls (Ctrl). Results are expressed as median (interquartile range) of copy number relative to control patients. ${ }^{*} p<0.05,{ }^{* *} p<0.001$ and ${ }^{* * *} p<0.0005$ using the Kruskal-Wallis test. 
ROC curves were calculated for each marker. As expected from the expression levels between control, AA and CRC, the area under the curve (AUC) values were $\geq 0.8$ for all markers for identifying CRC and three markers for identifying AA (Figure 2). The regrouping of the targets was then calculated for the two groups of markers, which can identify CRC only or AA and CRC. As copy numbers varied considerably between the targets, from 200 for MYC to 40,000 for CEACAM5, individual scores were determined for all targets by attributing a value of 0 to 3 for each patient sample based on the ROC curve cut-off values of the targets, as described in Materials and Methods. Then, an overall score for the each of the two groups of markers was determined for controls and patients with AA or CRC. The overall score for the six markers of the first group significantly recognized the samples from CRC patients vs. those of the controls while the overall scores of the three markers of the second group distinguished the samples from patients bearing CRC or AA from those of the controls (Figure 3).

\section{$A A$}

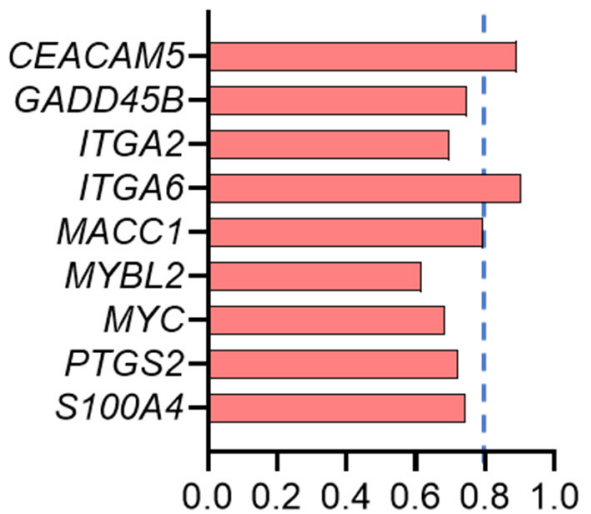

$\mathrm{CRC}$

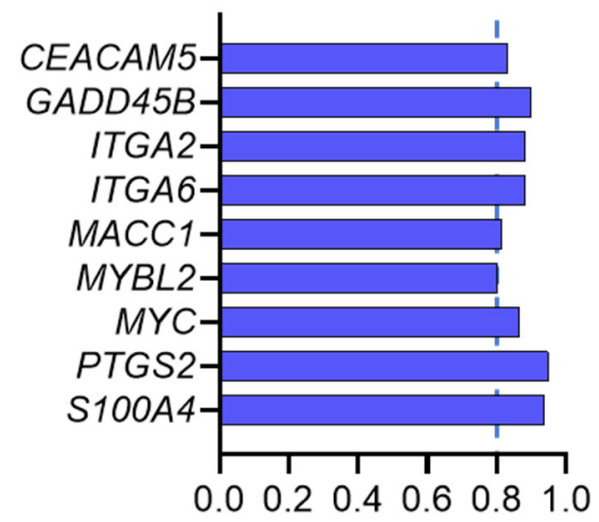

Figure 2. ROC curves were determined for the nine targets characterized in Figure 1 and areas under the curve were calculated to identify those equal or above 0.8 (dotted lines) for AA and CRC.
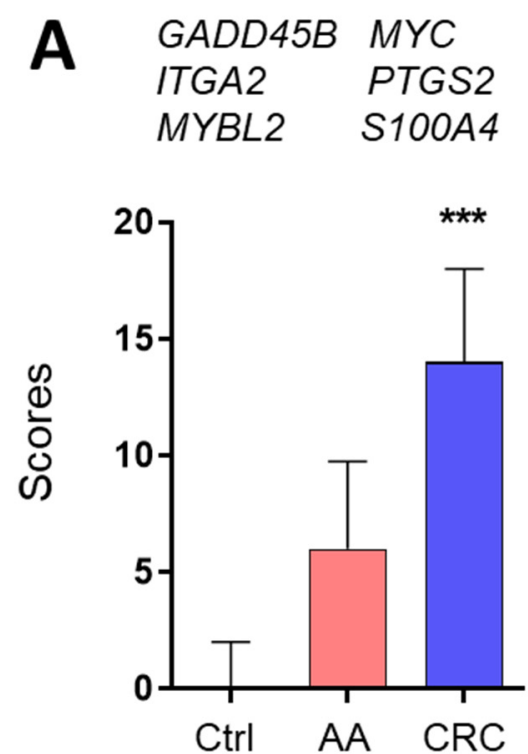

B CEACAM5 ITGA6 MACC1

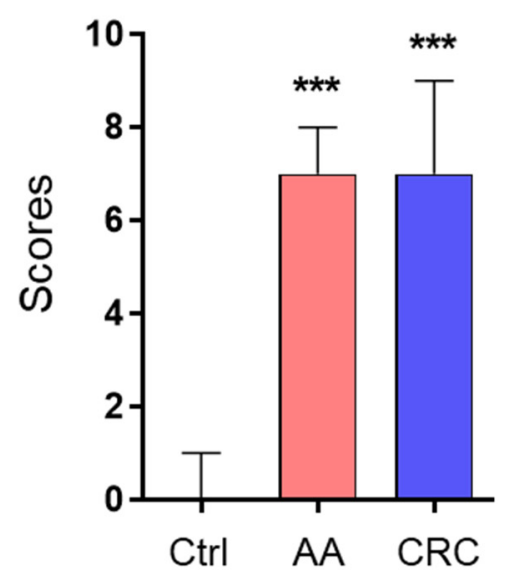

Figure 3. Based on the data from Figures 1 and 2, scores were calculated for the two groups of markers using an algorithm for combining the six targets significant for CRC (A) and the three targets significant for AA and CRC (B) lesions relative to controls. Results are expressed as median (interquartile range) of scores relative to control patients. ${ }^{* * *} p<0.0005$ using the Kruskal-Wallis test. 
ROC curves were then produced for the two groups of targets significant for CRC (Figure 3A, Group A) and for AA and CRC (Figure 3B, Group B). As shown in Table 2 (upper two rows) for $>95 \%$ specificity, group A (Gr. A) displayed $85.2 \%$ sensitivity for CRC but only $45 \%$ for AA while group B (Gr. B) showed 79\% and $75 \%$ sensitivity (for $95 \%$ specificity) for CRC and AA, respectively.

Table 2. Selection of the best combinations of targets.

\begin{tabular}{|c|c|c|c|c|c|c|c|c|c|c|c|c|c|}
\hline & & \multicolumn{6}{|l|}{ AA } & \multicolumn{6}{|l|}{ CRC } \\
\hline & & AUC & $\operatorname{Sen}^{1}$ & Spe ${ }^{1}$ & $\mathrm{YI}^{2}$ & $\begin{array}{c}\text { Sen }^{3} \text { Spe } \\
\geq 95 \%\end{array}$ & $\begin{array}{l}\text { Spe }{ }^{4} \text { Sen } \\
\geq 80 \%\end{array}$ & AUC & Sen $^{1}$ & Spe ${ }^{1}$ & $\mathrm{YI}^{2}$ & $\begin{array}{l}\text { Sen }^{3} \text { Spe } \\
\geq 95 \%\end{array}$ & $\begin{array}{l}\text { Spe }^{4} \text { Sen } \\
\geq 80 \%\end{array}$ \\
\hline $\begin{array}{c}\text { Gr. } \\
\text { A }\end{array}$ & & 0.819 & 79.1 & 87.10 & 0.66 & 45.30 & 51.61 & 0.969 & 85.19 & 96.97 & 0.86 & 85.19 & 100.0 \\
\hline Gr. B & & 0.917 & 91.67 & 83.87 & 0.76 & 75.00 & 83.87 & 0.914 & 79.01 & 96.97 & 0.76 & 79.01 & 83.87 \\
\hline Gr. B & $\stackrel{+}{\text { GADD45B }}$ & 0.900 & 75.00 & 87.88 & 0.63 & 70.83 & 72.73 & 0.923 & 79.01 & 96.97 & 0.76 & 79.01 & 87.88 \\
\hline Gr. B & + ITGA2 & 0.900 & 79.17 & 90.91 & 0.70 & 70.83 & 66.67 & 0.929 & 83.95 & 96.97 & 0.81 & 83.95 & 96.97 \\
\hline Gr. B & + MYBL2 & 0.915 & 79.17 & 93.94 & 0.73 & 75.00 & 78.79 & 0.924 & 85.19 & 93.94 & 0.79 & 80.25 & 96.97 \\
\hline Gr. B & + MYC & 0.918 & 83.33 & 93.94 & 0.77 & 66.67 & 93.94 & 0.939 & 85.19 & 94.94 & 0.79 & 80.25 & 96.97 \\
\hline Gr. B & + PTGS2 & 0.905 & 79.17 & 90.32 & 0.70 & 66.67 & 70.97 & 0.944 & 86.42 & 93.55 & 0.80 & 81.48 & 96.97 \\
\hline Gr. B & + S100A4 & 0.910 & 79.17 & 93.94 & 0.73 & 75.00 & 87.88 & 0.952 & 86.42 & 93.94 & 0.80 & 81.48 & 96.97 \\
\hline Gr. B & $+\underset{\text { S100A4 }}{+ \text { ITGA2 + }}$ & 0.897 & 79.17 & 90.91 & 0.69 & 70.83 & 84.85 & 0.958 & 86.42 & 93.94 & 0.80 & 82.72 & 96.97 \\
\hline Gr. B & $+\underset{\text { S100A4 }}{+ \text { ITGA2 + }}$ & 0.890 & 75.00 & 93.55 & 0.69 & 66.67 & 80.65 & 0.952 & 87.65 & 93.55 & 0.81 & 83.95 & 100.0 \\
\hline$\underset{B}{\text { Gr. }}$ & $\begin{array}{l}\text { + PTGS2 } \\
\text { + S100A4 }\end{array}$ & 0.910 & 83.33 & 87.10 & 0.70 & 75.00 & 87.10 & 0.961 & 88.89 & 96.77 & 0.86 & 88.89 & 96.97 \\
\hline
\end{tabular}

Gr A: GADD45B + ITGA2 + MYBL2 + MYC + PTGS2 + S100A4. Gr B: CEACAM5 + ITGA6 + MACC1. ${ }^{1}$ Sensitivities (Sen) and Specificities (Spe) were determined based on optimal cut-off values. ${ }^{2}$ YI: Youden Index. ${ }^{3}$ Sensitivity for specificity $\geq 95 \% .{ }^{4}$ Specificity for sensitivity $\geq 80 \%$. Bold (last row): Best combination.

Considering that the detection $75 \%$ of the AA could be achieved using the three markers of the group B (i.e., CEACAM5, ITGA6 and MACC1), we then assayed various combinations of markers belonging to the group $\mathrm{A}$ in order to improve CRC detection using a maximum of 5 targets while keeping AA detection at 75\% (Table 2). The results show that adding the two markers S100A4 and PTGS2 significantly improved the rate of CRC detection up to $89 \%$ (for $95 \%$ specificity) (Table 2, lower row). Corresponding ROC curves are provided in Figure 4A. FIT positivity was $29 \%$ in AA $(7 / 24)$ and $72 \%$ in CRC stage I-III (56/72). Interestingly, considering the result of the FIT in combination with the multitarget score further increased CRC detection up to $95 \%$ (for a $97 \%$ specificity), but had no significant effect on AA detection (Figure 4B).

As the ultimate goal of the study was to evaluate the feasibility of using the multitarget mRNA stool test in a clinical set-up, we evaluated the stability of the mRNA targets in stool samples subjected to various conditions of preservation that mimic the clinical reality. Stool samples were obtained from three controls and three patients diagnosed with CRC. Four of the identified targets in stools were selected for testing, including two for each group identified above: CEACAM5, ITGA6, ITGA2, and PTGS2. Conditions to be tested included conventional freezing at $-20{ }^{\circ} \mathrm{C}$ with and without a thaw cycle, conservation at $4{ }^{\circ} \mathrm{C}$ and conservation at room temperature $\left(23^{\circ} \mathrm{C}\right)$, for a 5 -day period. As shown in Figure S1, the mRNA targets were found to be relatively stable under all frozen and cooled conditions over the 5-day period while some individual variations were observed in samples maintained at room temperature. Score compilation of the data confirmed the relative stability of the targets for all conditions including ambient temperature for at least 3 days (Figure 5). 


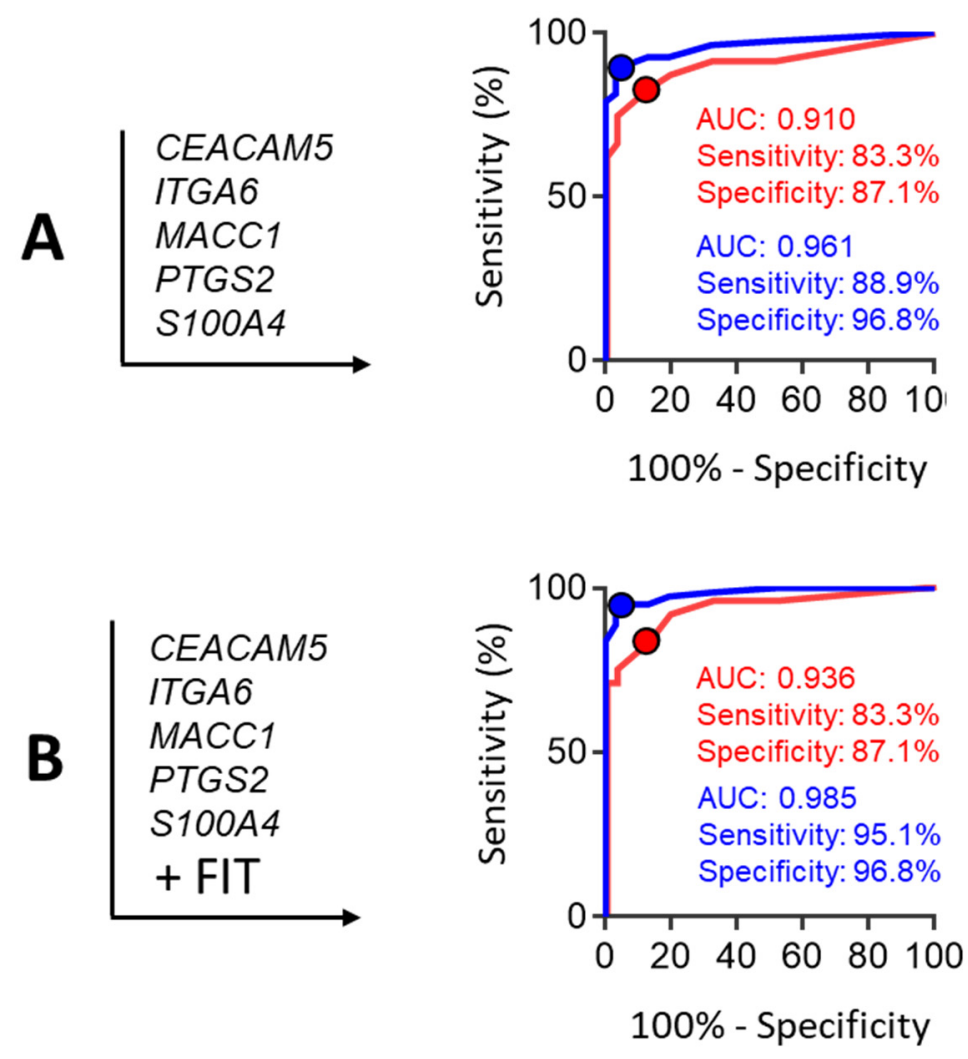

Figure 4. ROC curve analysis of an optimized combination of five of the targets for the detection of patients with AA or CRC as selected from data presented in Table 2. (A) ROC curve analysis of the combination of the three targets identified for detecting AA and CRC, CEACAM5, ITGA6 and MACC1 with the two stronger targets for detecting CRC, PTGS2 and S100A4, for AA and CRC. (B) Same combination as in A but including the FIT component. AUC is indicated and sensitivity and specificity are provided in $\%(95 \% \mathrm{CI})$.

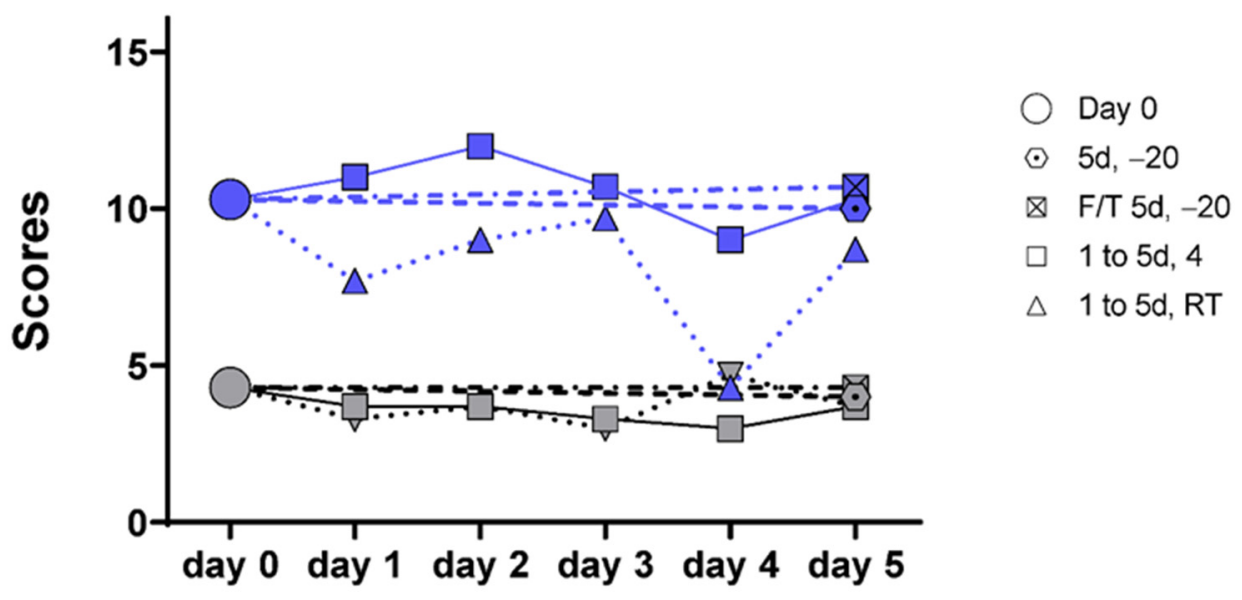

Figure 5. Target stability analyses in stool samples over a 5-day period. Target stability was tested under various conditions of conservation and target detection was monitored throughout the 5 days in samples maintained at $-20{ }^{\circ} \mathrm{C}$ with $(\mathrm{F} / \mathrm{T} 5 \mathrm{~d},-20)$ and without $(5 \mathrm{~d}-20)$ a thaw cycle, at $4{ }^{\circ} \mathrm{C}$ ( 1 to $5 \mathrm{~d}, 4)$ and at room temperature $(1$ to $5 \mathrm{~d}, \mathrm{RT})$. Data for individual targets in copy number are provided in Figure S1. Cumulative scores including the 4 tested targets PTGS2, CEACAM5, ITGA2 and ITGA6 showed that overall, the targets were relatively stable for the five days under all cooled conditions and for three days at room temperature for both controls (Gray symbols) and CRC (Blue symbols). 


\section{Discussion}

In this study, we confirm that a multitarget stool mRNA test represents a powerful assay for detecting patients with colorectal cancers and demonstrate its usefulness to also detect high risk adenomas. One interest of the procedure relies on its relative simplicity considering that high sensitivities and specificities can be obtained with a selection of only five targets, thus compatible with multiplex PCR in stool samples, an approach already in place in the clinic to investigate gastrointestinal infections [37,38].

One strength of the multitarget stool mRNA test presented herein is that transcripts are directly isolated from the stools by conventional extraction methods $[25,32]$ thus being compatible with automation rather than procedures that require enrichment protocols for exfoliated colorectal cells prior to RNA extraction and processing [25,39]. Another strength is the relatively low number of targets required to optimize the assay. It is worth mentioning that an important part of this proof-of-concept study was finding specific targets to identify samples from patients with AA among others that appear to be overrepresented in CRC and then selecting the strongest combination to allow the detection of both AA and CRC. Indeed, some of the targets have been previously assessed for CRC detection [25,32] but it is noteworthy that one of the best markers identified herein for CRC detection, $S 100 A 4$, is reported for the first time. In the same direction, ITGA6 has been previously reported to be a good candidate for the improvement of AA detection [32] while the current study show that sensitivity and specificity for AA detection can be further improved by combining ITGA6 with CEACAM5 and MACC1, two targets not yet tested before for this purpose. Further study in this direction would be assisted by the development of specific algorithms where a specific weight is assigned to each marker.

While we agree that our study is preliminary, based on a retrospective analysis of a cohort of patients, as addressed below, it is nevertheless interesting to contextualize the findings that this study, relying on the use of only five mRNA targets, allowed the detection of $75 \%$ of the samples obtained from patients with AA and $89 \%$ of the samples obtained from patients with CRC, using a specificity of $\geq 95 \%$. We chose to express the data using this optimal specificity which generates less than $5 \%$ of false positives in order to allow a fair comparison to other tests such as FIT as detailed above. Incidentally, integration of the FIT component to the mRNA data increased CRC sensitivity up to $95 \%$, consistent with the fact that the origins of exfoliated cells and blood in the stools are likely to be different [14-17]. Overall, a multitarget stool mRNA-FIT test allows the detection of $75 \%$ of the AA and $95 \%$ of the CRC with less than $4 \%$ of false positives. These numbers, although from a preliminary study, compared advantageously to any other screening test for colorectal cancerous lesions. As shown with the inclusion of the FIT component, diversification of target types improves sensitivity. In this context, it would be interesting to investigate the potential complementarity of the multitarget stool mRNA test with others approaches also involving stool-derived nucleic acids $[18,40,41]$ or proteins $[15,42]$. Incidentally, although the extra costs and specific organizational requirements of the multitarget stool mRNA test relative to the FIT are difficult to evaluate at this time, they should be substantially reduced if performed in conjunction with another nucleic acid-based stool test such as the already implemented multi-target stool DNA test [18].

Another finding from this study is the possibility of including a factor for predicting AA vs. CRC, which could provide pertinent information ahead of colonoscopy. Indeed, considered separately, the combination of the three targets CEACAM5, ITGA6 and MACC1 selected to predict AA provided $75 \%$ and $79 \%$ sensitivity (for $95 \%$ specificity) for AA and CRC, respectively and the two targets S100A4 and PTGS2 selected to improve CRC detection provided $29 \%$ and $80 \%$ sensitivity (for $95 \%$ specificity) for AA and CRC prediction, respectively, suggesting that using distinct repertoires of targets for AA and CRC could be used to improve patient stratification for colonoscopy. Specific analysis of S100A4 and PTGS2 scores for patients identified as positive in the multi-target stool mRNA test could contribute to discriminating between patients carrying AA vs. those with CRC 
considering that, for instance, a patient with a score $>4.5$ for S100A4 and PTGS2 displays a $17 \%$ probability of having an AA vs. $73 \%$ odds of having a CRC.

Finally, the assessment of target stability revealed that stool sample collection to perform the multitarget stool mRNA test does not require specific conditions, being relatively stable for at least 3 days, even at room temperature. Part of this relatively surprising observation may result from the possibility that mRNA degradation is prevented in exfoliated cells, which are the main source of host mRNA in the stools [25,39]. Another part results from the procedure used for selecting the mRNA targets. Incidentally, it was not surprising that only half of the 27 selected targets were amplified in stool samples. The efficient amplification of these targets was also dependent on the use of the TaqMan Gene Expression Assay which was found to be more sensitive and specific than conventional qPCR for stool samples [31] while requiring relatively short intact mRNA sequences.

The limitations of this study, as mentioned above, include the relatively small size of the cohort of patients providing the two sets of samples from only two sites and the fact that the samples were obtained retrospectively. Future investigations should include a larger and multicentric prospective study. However, the relatively low incidence of CRC in the asymptomatic population to be screened complicates this kind of study. Low scale prospective analyses on higher risk cohorts such as FIT positive patients could then be considered.

\section{Conclusions}

In conclusion, this study demonstrates the usefulness of host mRNAs as biomarkers to identify patients carrying curable colorectal cancers as well as precancerous lesions. In the context where various stool-based screening approaches are already implemented or in progress, with their strengths and weaknesses, we suggest that the inclusion of a multitarget stool mRNA component could contribute to getting closer to the "desirable features of a screening test" [3].

Supplementary Materials: The following are available online at https:/ / www.mdpi.com/2072-669 4/13/6/1228/s1, Figure S1: Target stability analyses in stool samples over a 5-day period.

Author Contributions: J.-F.B. designed the study and wrote the manuscript. E.H. and É.T. conducted the experiments and performed the statistical analyses. N.M. and S.K. contributed samples and analyzed the clinical data. All authors have read and agreed to the published version of the manuscript.

Funding: The work was supported by the Canadian Institutes of Health Research, grants number PPP133373, MOP97836 and PJT1773403 and by the Canada Chair Program, an internal grant from the Centre de recherche du Centre Hospitalier Universitaire de Sherbrooke and a research grant from ALIGO Innovation, a Quebec-based valorization society. None of these funding bodies had any role in the design of the study or the collection, analysis, and interpretation of data nor in the writing of the manuscript.

Institutional Review Board Statement: Two sets of patient samples were used in this study. The first set of samples was collected from patients and healthy controls from the Hamamatsu University School of Medicine with written informed consent. The study was approved by the Institutional Research Ethics Committee of the Hamamatsu University School of Medicine for sample collection and use as well as the Institutional Research Ethics Committee of the Centre Hospitalier Universitaire de Sherbrooke (CHUS) for the handling and analyses of the samples. The second set of samples was collected from healthy controls and patients diagnosed with CRC at the CHUS with written informed consent. The study was approved by the Institutional Research Ethics Committee of the CHUS on 9 December 2016 (ethic protocol \# 90-18) and then renewed yearly.

Informed Consent Statement: Informed consent was obtained from all subjects involved in the study.

Data Availability Statement: The data presented in this study are available on request from the corresponding author. 
Acknowledgments: The authors thank Maude Gerard for her help in the recruitment of patients for the Sherbrooke arm and Yvan Côté and Jorge Ganopolsky for suggestions in the design of the experiments to evaluate mRNA stability in stools.

Conflicts of Interest: The authors Elizabeth Herring, Éric Tremblay and Jean-François Beaulieu are inventors of the intellectual property owned by the Universite de Sherbrooke. The other authors have no conflict of interest to declare.

\section{References}

1. Ladabaum, U.; Dominitz, J.A.; Kahi, C.; Schoen, R.E. Strategies for colorectal cancer screening. Gastroenterology 2020, 158, 418-432. [CrossRef]

2. Manfredi, S.; Bouvier, A.M.; Lepage, C.; Hatem, C.; Dancourt, V.; Faivre, J. Incidence and patterns of recurrence after resection for cure of colonic cancer in a well defined population. Br. J. Surg. 2006, 93, 1115-1122. [CrossRef]

3. Robertson, D.J.; Imperiale, T.F. Stool testing for colorectal cancer screening. Gastroenterology 2015, 149, 1286-1293. [CrossRef] [PubMed]

4. Willyard, C. Screening: Early alert. Nature 2015, 521, S4-S5. [CrossRef]

5. Brenner, H.; Hoffmeister, M.; Stegmaier, C.; Brenner, G.; Altenhofen, L.; Haug, U. Risk of progression of advanced adenomas to colorectal cancer by age and sex: Estimates based on 840,149 screening colonoscopies. Gut 2007, 56, 1585-1589. [CrossRef] [PubMed]

6. Click, B.; Pinsky, P.F.; Hickey, T.; Doroudi, M.; Schoen, R.E. Association of colonoscopy adenoma findings with long-term colorectal cancer incidence. JAMA 2018, 319, 2021-2031. [CrossRef]

7. Schroy, P.C., 3rd; Lal, S.; Glick, J.T.; Robinson, P.A.; Zamor, P.; Heeren, T.C. Patient preferences for colorectal cancer screening: How does stool DNA testing fare? Am. J. Manag. Care 2007, 13, 393-400.

8. Lin, J.S.; Piper, M.A.; Perdue, L.A.; Rutter, C.M.; Webber, E.M.; O'Connor, E.; Smith, N.; Whitlock, E.P. Screening for colorectal cancer: Updated evidence report and systematic review for the US preventive services task force. JAMA 2016, 315, 2576-2594. [CrossRef]

9. Allison, J.E.; Fraser, C.G.; Halloran, S.P.; Young, G.P. Population screening for colorectal cancer means getting FIT: The past, present, and future of colorectal cancer screening using the fecal immunochemical test for hemoglobin (FIT). Gut Liver 2014, 8 , 117-130. [CrossRef]

10. Hundt, S.; Haug, U.; Brenner, H. Comparative evaluation of immunochemical fecal occult blood tests for colorectal adenoma detection. Ann. Intern. Med. 2009, 150, 162-169. [CrossRef]

11. Lee, J.K.; Liles, E.G.; Bent, S.; Levin, T.R.; Corley, D.A. Accuracy of fecal immunochemical tests for colorectal cancer: Systematic review and meta-analysis. Ann. Intern. Med. 2014, 160, 171-181. [CrossRef]

12. Laanani, M.; Coste, J.; Blotiere, P.O.; Carbonnel, F.; Weill, A. Patient, procedure, and endoscopist risk factors for perforation, bleeding, and splenic injury after colonoscopies. Clin. Gastroenterol. Hepatol. 2019, 17, 719-727.e13. [CrossRef]

13. Robertson, D.J.; Ladabaum, U. Opportunities and challenges in moving from current guidelines to personalized colorectal cancer screening. Gastroenterology 2019, 156, 904-917. [CrossRef]

14. Yu, Y.J.; Majumdar, A.P.; Nechvatal, J.M.; Ram, J.L.; Basson, M.D.; Heilbrun, L.K.; Kato, I. Exfoliated cells in stool: A source for reverse transcription-PCR-based analysis of biomarkers of gastrointestinal cancer. Cancer Epidemiol. Biomark. Prev. 2008, 17, 455-458. [CrossRef]

15. Ang, C.S.; Baker, M.S.; Nice, E.C. Mass spectrometry-based analysis for the discovery and validation of potential colorectal cancer stool biomarkers. Methods Enzymol. 2017, 586, 247-274. [CrossRef]

16. Berger, B.M.; Ahlquist, D.A. Stool DNA screening for colorectal neoplasia: Biological and technical basis for high detection rates. Pathology 2012, 44, 80-88. [CrossRef]

17. Koga, Y.; Yasunaga, M.; Katayose, S.; Moriya, Y.; Akasu, T.; Fujita, S.; Yamamoto, S.; Baba, H.; Matsumura, Y. Improved recovery of exfoliated colonocytes from feces using newly developed immunomagnetic beads. Gastroenterol. Res. Pract. 2008, $2008,605273$. [CrossRef] [PubMed]

18. Imperiale, T.F.; Ransohoff, D.F.; Itzkowitz, S.H.; Levin, T.R.; Lavin, P.; Lidgard, G.P.; Ahlquist, D.A.; Berger, B.M. Multitarget stool DNA testing for colorectal-cancer screening. N. Engl. J. Med. 2014, 370, 1287-1297. [CrossRef]

19. Ransohoff, D.F.; Sox, H.C. Clinical practice guidelines for colorectal cancer screening: New recommendations and new challenges. JAMA 2016, 315, 2529-2531. [CrossRef] [PubMed]

20. Lansdorp-Vogelaar, I.; van Ballegooijen, M.; Zauber, A.G.; Habbema, J.D.; Kuipers, E.J. Effect of rising chemotherapy costs on the cost savings of colorectal cancer screening. J. Natl. Cancer Inst. 2009, 101, 1412-1422. [CrossRef]

21. Neumann, P.J.; Cohen, J.T.; Weinstein, M.C. Updating cost-effectiveness-The curious resilience of the \$50,000-per-QALY threshold. N. Engl. J. Med. 2014, 371, 796-797. [CrossRef]

22. Imperiale, T.F.; Kahi, C.J. Cost-effectiveness of future biomarkers for colorectal cancer screening: Quantified futility or call for innovation? Clin. Gastroenterol. Hepatol. 2018, 16, 483-485. [CrossRef]

23. Haug, U.; Knudsen, A.B.; Lansdorp-Vogelaar, I.; Kuntz, K.M. Development of new non-invasive tests for colorectal cancer screening: The relevance of information on adenoma detection. Int. J. Cancer 2015, 136, 2864-2874. [CrossRef] 
24. Koga, Y.; Yasunaga, M.; Moriya, Y.; Akasu, T.; Fujita, S.; Yamamoto, S.; Kozu, T.; Baba, H.; Matsumura, Y. Detection of colorectal cancer cells from feces using quantitative real-time RT-PCR for colorectal cancer diagnosis. Cancer Sci. 2008, 99, $1977-1983$. [CrossRef]

25. Kanaoka, S.; Yoshida, K.; Miura, N.; Sugimura, H.; Kajimura, M. Potential usefulness of detecting cyclooxygenase 2 messenger RNA in feces for colorectal cancer screening. Gastroenterology 2004, 127, 422-427. [CrossRef]

26. Takai, T.; Kanaoka, S.; Yoshida, K.; Hamaya, Y.; Ikuma, M.; Miura, N.; Sugimura, H.; Kajimura, M.; Hishida, A. Fecal cyclooxygenase 2 plus matrix metalloproteinase 7 mRNA assays as a marker for colorectal cancer screening. Cancer Epidemiol. Biomark. Prev. 2009, 18, 1888-1893. [CrossRef]

27. Hamaya, Y.; Yoshida, K.; Takai, T.; Ikuma, M.; Hishida, A.; Kanaoka, S. Factors that contribute to faecal cyclooxygenase-2 mRNA expression in subjects with colorectal cancer. Br. J. Cancer 2010, 102, 916-921. [CrossRef]

28. Dydensborg, A.B.; Teller, I.C.; Groulx, J.F.; Basora, N.; Pare, F.; Herring, E.; Gauthier, R.; Jean, D.; Beaulieu, J.F. Integrin alpha6Bbeta4 inhibits colon cancer cell proliferation and c-Myc activity. BMC Cancer 2009, 9, 223. [CrossRef]

29. Groulx, J.F.; Giroux, V.; Beausejour, M.; Boudjadi, S.; Basora, N.; Carrier, J.C.; Beaulieu, J.F. Integrin alpha6A splice variant regulates proliferation and the Wnt/beta-catenin pathway in human colorectal cancer cells. Carcinogenesis 2014, 35, 1217-1227. [CrossRef]

30. You, Y.N.; Rustin, R.B.; Sullivan, J.D. Oncotype DX((R)) colon cancer assay for prediction of recurrence risk in patients with stage II and III colon cancer: A review of the evidence. Surg. Oncol. 2015, 24, 61-66. [CrossRef] [PubMed]

31. Herring, E.; Kanaoka, S.; Tremblay, E.; Beaulieu, J.F. A stool multitarget mRNA assay for the detection of colorectal neoplasms. Methods Mol. Biol. 2018, 1765, 217-227. [CrossRef]

32. Beaulieu, J.F.; Herring, E.; Kanaoka, S.; Tremblay, E. Use of integrin alpha 6 transcripts in a stool mRNA assay for the detection of colorectal cancers at curable stages. Oncotarget 2016, 7, 14684-14692. [CrossRef]

33. Herring, E.; Kanaoka, S.; Tremblay, E.; Beaulieu, J.F. Droplet digital PCR for quantification of ITGA6 in a stool mRNA assay for the detection of colorectal cancers. World J. Gastroenterol. 2017, 23, 2891-2898. [CrossRef] [PubMed]

34. Reck, M.; Tomasch, J.; Deng, Z.; Jarek, M.; Husemann, P.; Wagner-Dobler, I.; Consortium, C. Stool metatranscriptomics: A technical guideline for mRNA stabilisation and isolation. BMC Genomics 2015, 16, 494. [CrossRef]

35. Stauber, J.; Shaikh, N.; Ordiz, M.I.; Tarr, P.I.; Manary, M.J. Droplet digital PCR quantifies host inflammatory transcripts in feces reliably and reproducibly. Cell. Immunol. 2016, 303, 43-49. [CrossRef] [PubMed]

36. Dydensborg, A.B.; Herring, E.; Auclair, J.; Tremblay, E.; Beaulieu, J.-F. Normalizing genes for quantitative RT-PCR in differentiating human intestinal epithelial cells and adenocarcinomas of the colon. Am. J. Physiol. Gastrointest. Liver Physiol. 2006, 290, G1067-G1074. [CrossRef] [PubMed]

37. Maas, L.; Dorigo-Zetsma, J.W.; de Groot, C.J.; Bouter, S.; Plotz, F.B.; van Ewijk, B.E. Detection of intestinal protozoa in paediatric patients with gastrointestinal symptoms by multiplex real-time PCR. Clin. Microbiol. Infect. 2014, 20, 545-550. [CrossRef]

38. Becker, S.L.; Chatigre, J.K.; Gohou, J.P.; Coulibaly, J.T.; Leuppi, R.; Polman, K.; Chappuis, F.; Mertens, P.; Herrmann, M.; N'Goran, E.K.; et al. Combined stool-based multiplex PCR and microscopy for enhanced pathogen detection in patients with persistent diarrhoea and asymptomatic controls from Cote d'Ivoire. Clin. Microbiol. Infect. 2015, 21, 591.e1-591.e10. [CrossRef] [PubMed]

39. Barnell, E.K.; Kang, Y.; Wurtzler, E.M.; Griffith, M.; Chaudhuri, A.A.; Griffith, O.L.; Geneoscopy, S. Noninvasive detection of high-risk adenomas using stool-derived eukaryotic RNA sequences as biomarkers. Gastroenterology 2019, 157, 884-887.e3. [CrossRef]

40. Rengucci, C.; De Maio, G.; Menghi, M.; Benzi, F.; Calistri, D. Evaluation of colorectal cancer risk and prevalence by stool DNA integrity detection. J. Vis. Exp. 2020. [CrossRef]

41. Ahmed, F.E.; Ahmed, N.C.; Gouda, M.M.; Vos, P.W.; Bonnerup, C. RT-qPCR for fecal mature MicroRNA quantification and validation. Methods Mol. Biol. 2018, 1765, 203-215. [CrossRef] [PubMed]

42. Alvarez-Chaver, P.; Otero-Estevez, O.; Paez de la Cadena, M.; Rodriguez-Berrocal, F.J.; Martinez-Zorzano, V.S. Proteomics for discovery of candidate colorectal cancer biomarkers. World J. Gastroenterol. 2014, 20, 3804-3824. [CrossRef] [PubMed] 